tion this because some writers lay stress on the way in which you are to pass your finger into the bladder. In my view it is of little moment, because if you have made the opening at the vesical neck sufficiently large your finger will have no difficulty in following the groove of the staff into the bladder. There will be no fear of making a pouch with your finger in the loose tissue beneath it. You will have noticed that there was no bleeding in either case, and there is every reason to believe they will both do well. [Both cases recovered very satisfactorily.]

A few words about one or two of the preliminary steps: I allude to injection of the bladder, which some writers do not think necessary, and to pulling up of the penis and scrotum. I think the bladder should be fairly distended, because the weight of the water helps to steady it, because the recto-vesical pouch of peritoneum is pushed up (although this should not be in danger, yet it has been wounded more than once), because, as these cases tend to show, the walls of the bladder do not always collapse over the stone after the urine gushes out, and also because the base of the organ is brought lower down when it is moderately distended. The pulling up of the penis and scrotum is valuable because this proceeding stretches the urethra over the groove of the staff; it pulls the vesical neck lower down, and the urethral bulb is drawn up out of the way of the incision. The pulling up of the scrotum has the advantage of rendering the skin tense, of facilitating the first incision, and of permitting the angle of the staff to be better felt before operating.

The difficulties, then, of perineal lithotomy are, as you bave now made out, threefold : first, to find the groove of

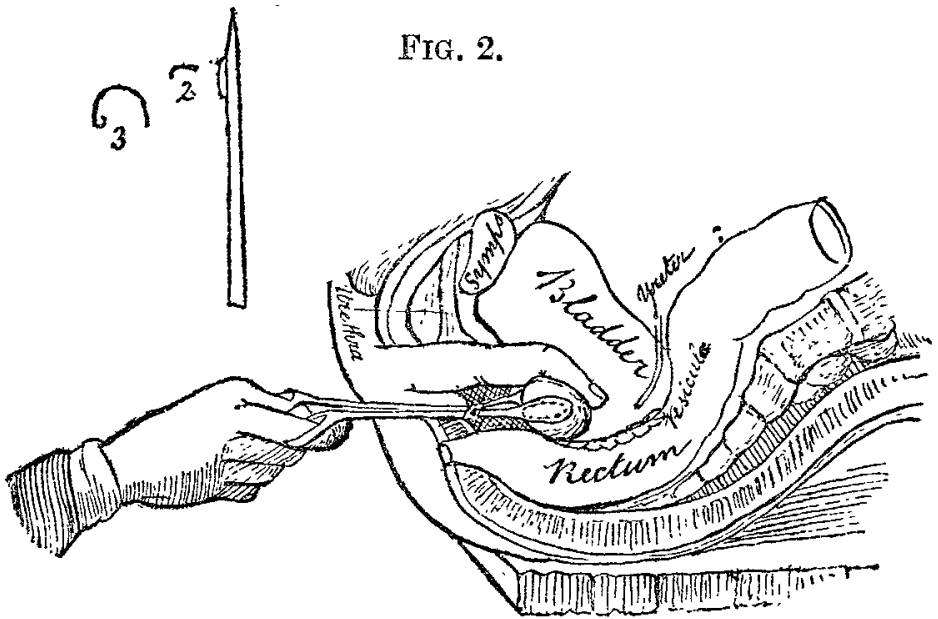

Showing the method of fixing the stoneat the neck of the bladder, and seizing it with the forceps. The back of the knife, with the catch attached, is shown. At 2 is the transverse section of this catch, and at 3 is a similar section of the staff, showing the arrangement to prevent the knife slipping from the groove. I have had a thick layer of rubber put over the edges of the stop of the staff, to prevent the knife being chipped.

the staff; second, to keep the knife safely in the groove, and push it steadily on to the stop at the vesical end of the staff; and, third, to extract the calculus. I have demonstrated to you practically, as well as described theoretically, how these are to be overcome; but I wish to explain to you some further steps which I was prepared to adopt in order to render every step of the operation as safe and simple as possible. These retractors, which are of a somewhat special shape, I had made for these operations, and if I had wished I could, with my thumb and finger, have pushed them gradually onwards towards the vesical orifice on either side of the staff, so as not only to obtain a view of the groove in the greater part of its extent, but, if necessary, to pass one of them along the groove into the bladder after the knife was withdrawn, and then by turning the handle to the floor I could have stretched the vesical opening enough to allow of the introduction of the index-finger. In fact, had the opening not been of sufficient size, and had I not liked to have made further use of the knife, I should have had three courses open to me, as the Premier is so fond of saying. I could have adopted the plan just described, or passed a grooved director, and then my finger between it and the staff, or have guided a pair of dressing forceps along the groove; and if 1 could not insinuate my finger between it and the staff, and had chosen to dilate, I could have done so with the forceps, and perhaps have got my finger in between its expanded blades. But these plans are best avoided, and they can be, by not being afraid of cutting with due judgment, skill, and anatomical knowledge; and if you have once made sure that you are in the groove, a bold incision is one -perhaps the greatest-secret of successful and brilliant lithotomy, always assuming that the cut does not exceed the limits which experience has approved.

The contretemps in the second case to which $I$ alluded arose in this way. The knife was very blunt, and I had to change it, moreover I had again to change to enlarge the opening, and in withdrawing the knife I unfortunately made an opening into the rectum, but that is now dealt with, and I trust the wound will unite, especially if the bowels be kept quiet. ${ }^{3}$ This accident has occurred in better hands than mine; still, it ought not to happen. I again warn you against it, but if you extract the stone safely, and therefore successfully, such a complication, which is not at all serious to the life of the patient, need not ' much disturb you, although if the wound do not heal, an annoying fistula, difficult to close, may result. I must not omit to mention that you must have a thoroughly reliable assistant, and one who will hold the staff steadily and safely in the bladder, and not let it slip out of that organ or deviate from the middle line. My senior, Mr. Rivington, was an invaluable assistant.

I think I have said all I had to say; and let me hope, gentlemen, that this brief and imperfect record of some of tue diffculties, dangers, and anxieties which I have experienced, and which have also unfortunately fallen to the lot of many other surgeons more eminent than I can hope to be, may lead, should a similar fate befall you, not to permanent discouragement, but to that better and more determined frame of mind which shall, in good time, carry you over difficulties on to success. I dare not venture to believe that even with the best preparation and intentions you will be free from mistakes, or from grave anxieties, first on account of your patient and then on your own behalf ; but whether you escape such calamities or not, remember always that to err is but to be human, to forgive is to imitate the divine. Prepare yourselves by frequent practice on the dead subject, see all the operations you can, and then do your best when the opportunity arises.

\section{ON A FORM OF}

\section{DYSPEPSIA OCCURRING IN INFANTS.}

By ARTHUR HILL HASSALL, M.D. LOND., LATE SENIOR PHYSICIAN TO THE ROYAL FREE HOSPITAL; FOUNDER OP AND CONSULTING PHYSICIAN to THE ROYAL NaTIONAL HOSPITAL FOR CONSUMPTION AND DISEASES OF THE CHEST.

IN addition to the ordinary classification of dyspepsia, based upon leading symptoms and conditions, there is yet another classification which might with advantage be adopted, to one or other division of which many cases of indigestion and bowel derangement occurring in infants, children, and adults might be referred. Thus there is one form of indigestion characterised by inability to digest with facility nitrogenous matters, and more particularly certain kinds of such matters. Many people cannot digest albumen, especially in the raw state, it often giving rise in the case of egg albumen to severe tormina; and, again, others cannot digest casein. Passing to the non-nitrogenous aliments there are many people who cannot digest fatty substances, others starchy or saccharine matters. On these data a really natural classification of several well-marked forms of indigestion might be based.

In the present communication I propose to deal with that form only which arises from the inability on the part of an infant to properly digest the casein of milk. A particularly fine infant had no other nourishment given it than its mother's milk for the first four months; during the whole of that period it was in the habit of throwing up after nearly every feeding a large quantity of coagulated casein, and the same was passed by stool in still greater amounts. The stools were almost colourless, with occasional patches of yellow or green; they were frequent, often very offensive, and there were constant attacks of distressing flatulent colic. Although so much casein was expelled without being digested, still the child was fairly

3 I laid the wound open into the rectum on the following day, and passed two deep stitches, and the little boy made an excellent recovery 
nourished, and its general health suffered much less than might have been expected, yet it did suffer, and increasingly, so that the conclusion was arrived at that it was better to wean the child. This was done, and it was next fed upon the milk of a single selected cow, properly diluted with water; this was given for some time, but with still worse results. Masses of casein, large enough almost to choke the child, were frequently thrown up; the stools, little else than casein, were perfectly white, and almost destitute of bile. The milk was changed several times for that of other cows, but no improvement took place. The motions were frequent, often immediately following the feeding. At length diarrhoea set in, the evacuations were very liquid, and on one or two occasions, when more solid, they were tinged with blood. Various remedies were employed, but without anything more than slight benefit, as antacids, carminatives, anodynes, and, lastly, astringents. The milk was boiled before being given, and diluted to a very considerable extent, but none of these means were effectual in putting a stop to the ejection of the undigested casein. Having regard to the large size of the masses of casein vomited, it was difficult to imagine that they could, in so bulky a form, be dissolved and digested, and it occurred to me that if the casein were broken up in the stomach into small particles, digestion would then much more readily follow. The child being between five and six months old, a mixture of malt and wheat flours, sugar, milk and water, properly mixed and prepared, was now given. The effects were immediate and most satisfactory ; the looseness and colic ceased, the motions became of soft consistence, of a natural and uniform yellow colour, and quite inoffensive. Now, this change in the child's condition was certainly not due to simple reduction in the amount of the casein given, for this had been tried before without avail ; but it was brought about, I believe, by the alteration in the physical condition of the casein effected by its admixture with the starchy matter contained in the food, whereby the casein was reduced to such minute particles as readily to allow of the solvent action of the gastric juice. I am confirmed in this view by what I have observed to happen in some cases where egg albumen fails to be digested, and gives rise to violent tormina. I have long had a case under my observation in which the most painful consequences result from eating cooked or uncooked eggs, or even the smallest quantity of egg in a sauce or ice. But this same individual can take eggs or the white of them with impunity provided they have been broken up by mixing and cooking with flour. Very young infants have no doubt a difficulty in digesting starchy matters, but I am inclined to think that this difficulty has been a good deal exaggerated, and has often prevented small quantities of farinaceous food being given when they would have been very serviceable. In the case related, the stools were specially tested several times for starch, very small quantities of which only were found. But it may be said, since malt flour was used, that the starch was transformed into sugar before the food was given; this would, however, only be true to a certain extent. I have made trial of nearly all the so-called "malted" foods now in the market, following strictly the methods of preparation described, but I have invariably found that a very large proportion of the starchy matter remains untransformed into maltose. It should be understood that what are called malted foods contain for the most part simply a proportion of malt flour, the foods themselves not having been subjected to any malting process.

Although in the present communication I bave only referred to a single case, the form of dyspepsia described is of very common occurrence in infants during the period of lactation. I may mention, in conclusion, that on one occasion, the child being perfectly well, the flour was suspended for a day or two, and milk-and-water only given; this was speedily followed, as before, by the ejection of the curd, and attacks of tormina.

San Remo.

Sanitary Institute of Great Britain.-The announcement of the award of the prize of $£ 200$, offered by the Rev. E. Wyatt Edgell for an essay on the "Range of Hereditary Tendencies in Health and Disease," will be made by the adjudicators at the first ordinary meeting of the institute for the session 1881-82, which will be held on Wednesday, Dec. 7th, at 7.45 P.M. The inaugural address will be delivered by Dr. Alfred Carpenter.

\section{GASTROSTOMY}

WITH TWO CASES IN WHICH THE OPERATION WAS PERFORMED FOR MALIGNANT STRICTURE OF THE CESOPHAGUS. ${ }^{1}$

By A. F. McGILL, F.R.C.S.,

LECTURER ON ANATOMY AT THE LEEDS SCHOOL OF MEDICINE.

OF the two following cases, one was successful and the patient is still alive, nearly four months after the operation; in the other, death occurred on the seventh day.

CASE 1.-Mrs. L_, aged thirty-six, was first seen by me on July 4th, 1881. She was suffering from well-marked symptoms of malignant stricture of the osophagus, which was situated at the junction of the pharynx and œsophagus behind the cricoid cartilage. In this position the new growth could be felt. No instrument could be passed. beyond this point. She was greatly wasted, but otherwise her condition was fairly good. She had first noticed diffi. culty in swallowing solids twelve months previously. For the last three months she has taken nothing but liquids. the quantity taken has gradually decreased, till now she is unable to take more than half a pint of nourishment in the twenty-four hours. As a consequence she complains much of hunger and of a burning thirst. Under the circum. stances of the case it scemed to me that there was no time for delay. I consequently advised gastrostomy, and, the patient being willing, performed the operation on July 6th. The patient being placed under ether, and the carbolic spray playing on the part to be incised, an incision two inches in length was made from the left linea semilunaris outwards for about two inches parallel to the costal cartilages, and distant from them half an inch. The small amount of bleeding that occurred being stopped by torsion, the peritoneum was opened for the same length. The greater curvature of the stomach with the omentum attached was exposed, and the anterior surface of the stomach about an inch from the curvature was attached to the abdominal wall by thirteen thin silver-wire sutures. The piece of stomach visible after the stitehes had been inserted was about one inch in diameter. The wound was then dressed with salicylic silk. -July 10th: Has not lost strength since the operation. Has been fed with Slinger's nutrient suppositories, one of which has been given every four hours. They have all been retained with the exception of one, which was returned with a motion. The patient has also sucked a considerable quantity of ice, administered to allay the burning thirst, and yesterday she swallowed a few teaspoonfuls of iced milk. She has been much troubled by pain in the seat of the wound, which has been aggravated by coughing; for this small doses of morphia have been administered. Her temperature was $100^{\circ}$ the morning after the operation, since then it has been normal. To-day the stomach is opened by a small crucial incision made with a tenotomy knife. Some slight difficulty was experienced owing to inability to fill the stomach well. A piece of india-rubber tubing was introduced, and four ounces of milk and egg injected by a Higginson's syringe. From this time the progress was in every way satisfactory. Peptonised milk was substituted for a few days for the milk and egg as it was found that this caused considerable pain, and was apparently not digested. The sutures were removed at intervals, the last on July 12th. On this day an india. rubber tracheotomy-tube was introduced through the abdominal wound into the stomach. Into this tube a glass funnel was inserted when it was necessary to give food; liquids were poured down it, and meat and bread finely divided were pushed into the stomach by means of a bougie or $a$ piece of stick. The patient gained strength rapidly, and three weeks after the operation was able to sit up, and go downstairs. About this time her breathing became heavy and laboured, owing to the malignant growth pressing on the larynx. In August I was away from Leeds, and my friend, Mr. Robson, kindly took charge of the patient for me. On Aug. 17th he found her suffering from extreme dyspnoea, caused apparently not only by direct pressure, but also by spasm of the glottis. He performed tracheotomy with immediate relief. Since then she has gone on with comparative comfort, but it is evident that owing to the

1 Read before the Leeds and West Riding Medico-Chirurgical Society 